\title{
Abnormal metabolism of arachidonic acid in chronic inflammatory bowel disease: enhanced release of leucotriene $\mathrm{B}_{4}$ from activated neutrophils
}

\author{
O H NIELSEN, I AHNFELT-RØNNE*, AND J ELMGREEN \\ From the Department of Medical Gastroenterology C, Herlev Hospital, University of Copenhagen, and \\ *Department of Pharmacology, Leo Pharmaceutical Products, Ballerup, Denmark
}

SUMMARY The metabolism of endogenous arachidonic acid P(AA) was investigated in activated neutrophils from 20 patients with Crohn's disease, 20 with ulcerative colitis, and 25 healthy volunteers. $1{ }^{14} \mathrm{C}-\mathrm{P}(\mathrm{AA})$ was incorporated into intracellular pools of phospholipids prior to activation of the cells with ionophore A23187 and analyses of released arachidonic acid metabolites by thin layer chromatography. Total release of radioactivity expressing the release of arachidonic acid and its metabolites, was equal in the experimental and control groups, which suggests a normal substrate availability. In contrast, there was a marked increase in the relative release of leucotriene $\mathrm{B}_{4}\left(\mathrm{LTB}_{4}\right)$ and its $\omega$-oxidation products, 20-hydroxy-LTB $\mathrm{LT}_{4}\left(20-\mathrm{OH}-\mathrm{LTB}_{4}\right)$ and 20-carboxy-LTB $\mathrm{LT}_{4}$ (20-COOH-LTB ${ }_{4}$ ), with $\mathrm{LTB}_{4}$ values exceeding the reference interval in seven of 20 patients with Crohn's disease, median $8 \cdot 7 \%$, and in six of 20 patients with ulcerative colitis, median $7 \cdot 7 \%$, as compared with a median of $5.3 \%$ in healthy volunteers. Furthermore, a decreased release of unmetabolised arachidonic acid, correlating inversely with the release of $\mathrm{LTB}_{4}$ in all experimental and control groups, and normal values for the production of other metabolites of arachidonic acidfor example, 5-hydroxyeicosatetraenoic acid (5-HETE) and 12-hydroxyheptadecatrienoic acid (HHT), point to an enzymatic abnormality such as increased activity of leucotriene B synthetase. An increased capacity for release of $\mathrm{LTB}_{4}$, the major pro-inflammatory metabolite of arachidonic acid lipoxygenation by polymorphonuclear leucocytes, may contribute to perpetuation of the inflammation and to tissue destruction in chronic inflammatory bowel disease. Our findings agree with previous reports of an increased release of $\mathrm{LTB}_{\mathbf{4}}$ by the colonic mucosa in this condition.

Polymorphonuclear leucocytes possibly play a role in the pathogenesis of chronic inflammatory bowel disease. Involvement of complement ${ }^{1-3}$ with resulting release of the chemotactic split product $\mathrm{C}^{4} \mathrm{a}^{4}$ thus may account for their vast numbers in the colonic exudate of patients with ulcerative colitis. ${ }^{56}$ Local accumulation and activation of this cellular element of inflammation with release of toxic oxygen metabolites, lysosomal enzymes, and metabolites of arachidonic acid, such as leucotriene $\mathrm{B}_{4}\left(\mathrm{LTB}_{4}\right)$, the less potent $\omega$-oxidation products, $20-\mathrm{OH}-\mathrm{LTB}_{4}$ and 20-COOH-LTB ${ }_{4}$, and 5-hydroxyeicosatetraenoic

Address for correspondence: Ole Haagen Nielsen, Department of Medical Gastroenterology C, Herlev Hospital, University of Copenhagen, Herlev Ringvej, DK-2730 Herlev, Denmark.

Received for publication 30 May 1986. acid (5-HETE) accordingly may contribute to perpetuation of inflammation and tissue destruction in chronic inflammatory bowel disease as it does in rheumatoid arthritis. ${ }^{7}$

Biopsy specimens of affected colonic mucosa from patients with chronic inflammatory bowel disease show increased production of the lipoxygenase products of arachidonic acid, and increased release of prostaglandins and leucotrienes has been shown in vitro ${ }^{89}$ and in vivo in patients with ulcerative colitis. ${ }^{10,11}$ The cell type and stimulus responsible for this production of inflammatory mediators have not yet been identified.

A recent study showed a marked abnormality in the oxidative metabolism of polymorphonuclear leucocytes in Crohn's disease as assessed by the release of hydrogen peroxide $\left(\mathrm{H}_{2} \mathrm{O}_{2}\right)$ and superoxide 
Table 1 Clinical data of patients with chronic inflammatory bowel disease

\begin{tabular}{|c|c|c|c|c|c|c|c|c|c|c|}
\hline \multirow[t]{2}{*}{ Group } & \multirow[t]{2}{*}{ No. } & \multirow{2}{*}{$\begin{array}{l}A g e^{*} \\
(y r)\end{array}$} & \multicolumn{2}{|c|}{ Sex } & \multicolumn{2}{|c|}{ Disease activity } & \multicolumn{3}{|l|}{ Disease site } & \multirow{2}{*}{$\begin{array}{l}\text { Disease* } \\
\text { duration } \\
(y r)\end{array}$} \\
\hline & & & $\sigma^{\prime \prime}$ & $q$ & Remission & $\begin{array}{l}\text { Active } \\
\text { stages }\end{array}$ & Small bowel & $\begin{array}{l}\text { Small bowel } \\
+ \text { colon }\end{array}$ & Colon & \\
\hline Crohn's disease & 20 & $48(18-79)$ & 7 & 13 & 11 & 9 & 6 & 8 & 6 & $10(2-24)$ \\
\hline Ulcerative colitis & 20 & $52(20-75)$ & 8 & 12 & 13 & 7 & - & - & 20 & $10(1 / 2-30)$ \\
\hline Healthy volunteers & 25 & $41(17-68)$ & 9 & 16 & - & - & - & - & - & - \\
\hline
\end{tabular}

${ }^{*}$ Median, range in brackets.

anions $\left(\mathrm{O}_{2}^{-}\right)$after activation. ${ }^{12}$ The aim of the present study was to assess the capacity of neutrophils for activation of arachidonic acid metabolism in untreated chronic inflammatory bowel disease patients.

\section{Methods}

\section{PATIENTS}

Twenty consecutive outpatients with well established diagnoses of Crohn's disease ${ }^{13}$ and ulcerative colitis ${ }^{13}$ were included in the study. Essential clinical parameters are given in Table 1. Disease activity in Crohn's disease was scored according to Harvey and Bradshaw ${ }^{14}$ with remission defined as less than five points, and in ulcerative colitis according to Tvede $e t$ $a l .{ }^{15}$ None of the patients had received specific drug treatment within the preceding four weeks, and none of the ulcerative colitis patients were colectomised or had rectal involvement only.

Informed consent was obtained from all patients and healthy volunteers, after verbal and written information, and the study was approved by the Scientific Ethical Committee of the Copenhagen County.

\section{NEUTROPHIL FUNCTION TEST}

Neutrophils were isolated from EDTA-blood $(0 \cdot 2$ $\mathrm{mmol} / \mathrm{l})$, with a recovery of $45 \%$ and a purity of more than $95 \%$, by (1) methyl-cellulose $(0.8 \%)$ sedimentation of erythrocytes, (2) washing and gradient centrifugation of 'buffy coat' leucocytes according to Böyum, ${ }^{16}$ and finally (3) hypotonic lysis of residual erythrocytes. Incorporation of $1-{ }^{14} \mathrm{C}$ arachidonic acid

Table 2 Total radioactivity released by $1-{ }^{14} \mathrm{C}-\mathrm{A}$ A labelled $P M N$ s during activation. Medians are given with ranges in brackets

\begin{tabular}{lll}
\hline Group & No. & $\begin{array}{l}\text { Radioactivity in } \\
10^{2} B q / 5 \times 10^{6} P M N s\end{array}$ \\
\hline Crohn's disease & 20 & $7 \cdot 3(3 \cdot 9-11 \cdot 1)$ \\
Ulcerative colitis & 20 & $6 \cdot 5(2 \cdot 8-11 \cdot 1)$ \\
Healthy volunteers & 25 & $6 \cdot 7(2 \cdot 6-9 \cdot 9)$ \\
\hline
\end{tabular}

$\left(37 \times 10^{3}\right.$ Becquerel $\left.(\mathrm{Bq}) / \mathrm{ml}, 2.2 \times 10^{9} \mathrm{~Bq} / \mathrm{mmol}\right)$ (Amersham International, UK) with labelling of intracellular pools of phospholipids ${ }^{17}$ proceeded for five hours at $37^{\circ} \mathrm{C}$ under $5 \%$ carbon dioxide and $95 \%$ atmospheric air in RPMI $1640\left(0.5 \times 10^{7}\right.$ cells $\left./ \mathrm{ml}\right)(5 \%$ autologous serum). After removal of excess extracellular arachidonic acid by washing, the cells were challenged with calcium ionophore A23187 (Calbiochem, La Jolla, California, USA) $(10 \mu \mathrm{M}, 15$ min). Released eicosanoids were extracted with dichloromethane: methanol; $2: 1$, separated by thin layer chromatography (developing solvents I: chloroform: methanol: acetic acid: water; 90:9:1:0.65, II: ethylacetate: iso-octane: acetic acid: water; 55:25:10:50) and quantified by autoradiography and laser densitometry. ${ }^{17}$ All analyses were done singly, and the intra-assay coefficient of variation for release of arachidonic acid metabolites was approximately $15 \% .{ }^{17}$

The specific activity of the arachidonic acid metabolites, LTB $_{4}$ and 5-HETE, was determined by quantitative high pressure liquid chromatography ${ }^{17}$ of samples from patients with Crohn's disease, which had the highest release of activity, and healthy volunteers.

\section{STATISTICAL ANALYSIS}

All values are given as medians and ranges. The data were analysed by a rank sum test for unpaired variables, and a $p$ value of less than 0.05 was considered significant. Linear correlation between released ${ }^{14} \mathrm{C}$-AA and ${ }^{14} \mathrm{C}$ - $\mathrm{LTB}_{4}$ was evaluated by the Pearson correlation procedure.

\section{Results}

Total radioactivity released, representing arachidonic acid and its metabolites, was equal in patients and control groups (Table 2).

The relative distribution of arachidonic acid and biologically active metabolites was abnormal in the patients. The 5-lipoxygenase product, $\mathrm{LTB}_{4}$, was increased in seven of 20 patients with Crohn's disease $(p<0.01)$ and in six of 20 patients with ulcerative 


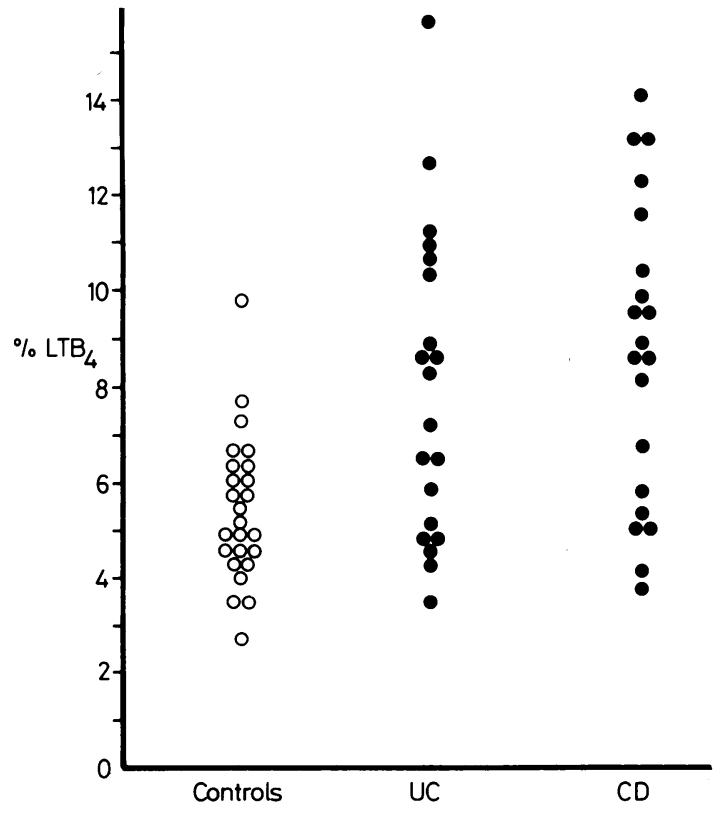

Fig 1 Relative release of the 5-lipoxygenase product, $1-{ }^{14} \mathrm{C}$ $\mathrm{LTB}_{4}$, expressed in per cent of total radioactivity released by activated neutrophils from healthy volunteers (controls) and patients with ulcerative colitis (UC) and Crohn's disease (CD).

colitis $(\mathrm{p}<0.01)$ as compared with the healthy volunteers (Fig. 1 and Table 3). Furthermore, the two $\omega$ oxidation products, 20-OH-LTB ${ }_{4}$ and $20-\mathrm{COOH}-$ $\mathrm{LTB}_{4}$, which were not resolved in the TLC-system I, were raised in parallel with $\mathrm{LTB}_{4}$ (Table 3 ). In additional experiments using TLC-system II, which separates $20-\mathrm{OH}-\mathrm{LTB}_{4}$ and $20-\mathrm{COOH}-\mathrm{LTB}_{4}$, the ratio between these two compounds was found to be median $3 \cdot 4: 1(1 \cdot 9-5 \cdot 5, n=10)$. In contrast, the values for the less potent lipoxygenase metabolite, 5HETE, and for the cyclo-oxygenase metabolite, HHT, did not differ between patients and controls (Table 3) indicating an increased total capacity for metabolising endogenously released arachidonic acid (Fig. 2).

An inverse correlation between released ${ }^{14} \mathrm{C}$-AA and ${ }^{14} \mathrm{C}-\mathrm{LTB}_{4}$ expressed in per cent of total released radioactivity could be established in each of the three groups, ulcerative colitis patients $(\mathrm{r}=-0 \cdot 815$; $\mathrm{p}<0 \cdot 01)$, Crohn's disease patients $(r=-0.875$; $\mathrm{p}<0.01)$, and healthy volunteers $(r=-0.806$; $\mathrm{p}<0.01)$.

The specific activity of $\mathrm{LTB}_{4}$ was equal in the two groups tested, $4 \cdot 1 \times 10^{8} \mathrm{~Bq} / \mathrm{mmol}$ (range $2 \cdot 9-5 \cdot 5$ ) and $5.4 \times 10^{8} \mathrm{~Bq} / \mathrm{mmol}$ (range 3.4-6.9) in patients with Crohn's disease and in healthy volunteers, respectively.

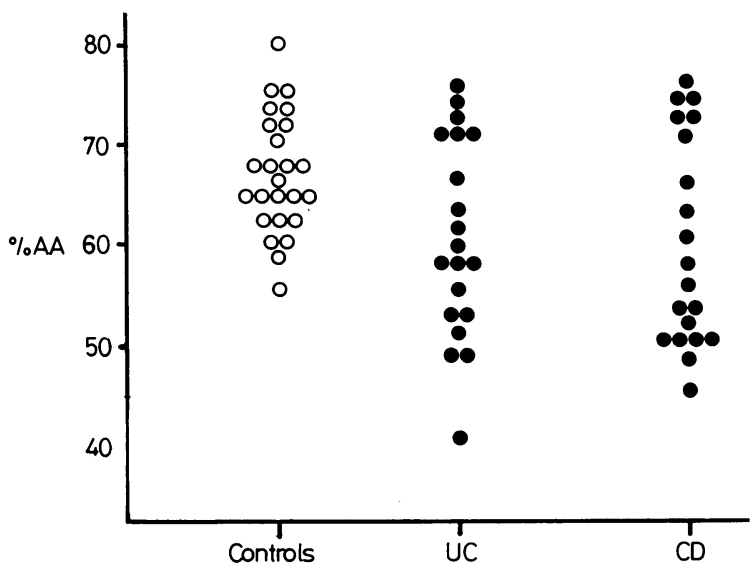

Fig 2 Relative release of unmetabolised $1{ }^{14} \mathrm{C}$ arachidonic acid $(A A)$ expressed in per cent of total radioactivity released by activated neutrophils from healthy volunteers (controls) and patients with ulcerative colitis (UC) and Crohn's disease $(C D)$.

None of the data correlated with clinical scores of disease activity, with duration of the disease, or with the site of intestinal involvement.

\section{Discussion}

Arachidonic acid is metabolised by oxygenation through separate pathways ${ }^{18}$ of which the 5lipoxygenase pathway leading to the inflammatory mediators $\mathrm{LTB}_{4}$ and 5-HETE seems to be the major route in human polymorphonuclear leucocytes. ${ }^{19}$ Increased release of these metabolites by the colonic mucosa in ulcerative colitis ${ }^{841120}$ may reflect release from inflammatory polymorphonuclear leucocytes, at least as judging by animal experiments. ${ }^{21}$ Our data suggest an underlying enzymatic defect of the circulating neutrophil. As the enzyme responsible for leucotriene synthesis, 5-lipoxygenase, has been shown to exhibit an absolute requirement for calcium ions, ${ }^{22}$ we have chosen to study the stimulation induced by calcium ionophore A23187. Although this is an unphysiologic agent it is assumed to produce the maximal synthesis of leucotrienes in response to calcium influx. The procedure therefore reflects the total capacity for leucotriene synthesis in human polymorphonuclear leucocytes. Activated polymorphonuclear leucocytes revealed an increased capacity for metabolising endogenously released arachidonic acid into $\mathrm{LTB}_{4}$ and the less potent $\omega$ oxidation products $-20-\mathrm{OH}-\mathrm{LTB}_{4}$ and $20-\mathrm{COOH}$ $\mathrm{LTB}_{4}{ }^{23}$ whereas the values for 5-HETE and the cyclo-oxygenase metabolites were normal. This finding does not reflect increased labelling of membrane phospholipids with $1-{ }^{14} \mathrm{C}$-AA as high pressure liquid 
Table 3 Release of arachidonic acid $(A A)$ and its main metabolites by activated neutrophils in healthy volunteers and patients with ulcerative colitis and Crohn's disease. Values are given in per cent of total radioactivity released and expressed in median values with ranges in brackets

\begin{tabular}{|c|c|c|c|c|c|c|}
\hline Group & No. & $\begin{array}{l}20-\mathrm{OH}-\mathrm{LTB} \mathrm{B}_{4} / \\
20-\mathrm{COOH}-\mathrm{LTB}_{4}\end{array}$ & $\mathrm{LTB}_{4}$ & 5-HETE & $H H T$ & $A A$ \\
\hline Crohn's disease & 20 & $4 \cdot 3^{*}(2 \cdot 1-9 \cdot 1)$ & $8 \cdot 7^{*}(3 \cdot 9-14 \cdot 2)$ & $16 \cdot 6(10 \cdot 5-19 \cdot 6)$ & $2 \cdot 3(0 \cdot 9-5 \cdot 2)$ & $56 \cdot 8^{*}(45 \cdot 3-75 \cdot 7)$ \\
\hline Ulcerative colitis & 20 & $4 \cdot 2 \dagger(1 \cdot 8-13 \cdot 2)$ & $7 \cdot 7 *(3 \cdot 5-15 \cdot 8)$ & $16 \cdot 3(10 \cdot 8-21 \cdot 3)$ & $2 \cdot 0(0 \cdot 8-5 \cdot 0)$ & $59 \cdot 8 \ddagger(41 \cdot 5-73 \cdot 5)$ \\
\hline Healthy volunteers & 25 & $2 \cdot 7(1 \cdot 1-6 \cdot 0)$ & $5 \cdot 3(2 \cdot 8-9 \cdot 6)$ & $14.9(9.5-19.4)$ & $2 \cdot 2(1 \cdot 0-5 \cdot 3)$ & $67 \cdot 0(56 \cdot 2-80 \cdot 4)$ \\
\hline
\end{tabular}

${ }^{*} \mathrm{p}<0 \cdot 01 . \dagger \mathrm{p}<0 \cdot(22 . \neq \mathrm{p}<0 \cdot 03$.

chromatography analyses of the 5-lipoxygenase products revealed that the specific activation was equal in the groups tested. Increased activity of $\mathrm{LTB}_{4}$ in the gut mucosa may hypothetically lead to accumulation of more neutrophils and thus to perpetuation of the chronic inflammation, $\mathrm{LTB}_{4}$ being a well established activator of oxygen metabolism, adherence, aggregation, and chemotaxis in neutrophils. ${ }^{24}$ The two catabolites of $\mathrm{LTB}_{4}, 20-\mathrm{OH}-\mathrm{LTB}_{4}$ and $20-\mathrm{COOH}-\mathrm{LTB}_{4}$ were also found to be raised in chronic inflammatory bowel disease, which indicates that the $\omega$ hydroxylase activity was not defective..$^{25}$

The combined finding of an increased relative release of $\mathrm{LTB}_{4}$, and a decreased contribution by arachidonic acid to total radioactivity released is highly suggestive of an intracellular, enzymatic abnormality in chronic inflammatory bowel disease such as an increased leucotriene B synthetase activity. On the other hand, it cannot be excluded that a defective hydrogen peroxide production ${ }^{12}$ may contribute to the enhanced $\mathrm{LTB}_{4}$ level seen in Crohn's disease patients, as hydrogen peroxide degrades leucotrienes unspecifically. ${ }^{26}$ Other cell types playing a role in chronic inflammation, for instance tissue macrophages, may show similar changes, but have not so far been investigated. ${ }^{27}$

The increased release of $\mathrm{LTB}_{4}$ does not suggest an initiating pathophysiologic role of arachidonic acid metabolites. $\mathrm{LTB}_{4}$ is a soluble mediator of inflammation that may amplify and modulate an inflammatory response already present, essentially by its potential for activating cellular elements by inflammation, ${ }^{24}$ but this is not likely to be a primary event. ${ }^{2 x}$

The described defective metabolism of arachidonic acid may be normalised by steroids, sulfasalazine, and 5-aminosalicylic acid all of which inhibit various steps of the arachidonic acid metabolism and are effective in the treatment of chronic inflammatory bowel disease. Thus, steroids induce the synthesis of phospholipase inhibitors (lipocortin) in vivo, ${ }^{29}$ whereas sulfasalazine and 5-aminosalicylic acid inhibit the 5-lipoxygenase activity in vitro. ${ }^{30}$

The data presented may cause reflections of a possible similarity between chronic inflammatory bowel disease and chronic granulomatous disease, since in both conditions polymorphonuclear leucocytes show an enhanced capacity for releasing leucotrienes. ${ }^{26}$ The intestinal granulomas in Crohn's disease and chronic granulomatous disease cannot be differentiated from each other on morphological criteria. $^{31}$

More information about the complex way in which arachidonic acid is metabolised in the diseased and normal intestine may provide a base for further rational approaches in the treatment of chronic inflammatory bowel disease.

High pressure liquid chromatography analyses were kindly carried out by Klaus Bukhave and Jørgen Rask-Madsen. The authors are grateful to Helma Furhauge, Hanne Kargaard, Bente Nielsen, and Kirsten Kaas Vad for skilful technical assistance. This work was supported by the Foundation of 1870 , handelsgartner Ove Villiam Buhl Olesen's and ægtefælle Edith Buhl Olesen's Foundation, Jacob Madsen's and hustru Olga Madsen's Foundation, and the Danish Medical Research Council.

\section{References}

1 Hodgson HJF, Potter BJ, Jewell DP. C3 metabolism in ulcerative colitis and Crohn's disease. Clin Exp Immunol 1977; 28: 490-5.

2 Potter BJ, Brown DCJ, Watson A, Jewell DP. Complement inhibitors and immunoconglutinins in ulcerative colitis and Crohn's disease. Gut 1980; 21: 1030-4.

3 Elmgreen J, Berkowicz A, Sørensen H. Hypercatabolism of complement in Crohn's disease - assessment of circulating C3c. Acta Med Scand 1983; 214: 403-7.

4 Elmgreen J, Both H, Binder V. Familial occurrence of complement dysfunction in Crohn's disease: correlation with intestinal symptoms and hypercatabolism of complement. Gut 1985; 26: 151-7.

5 Riis P. The cytology of inflammatory exudate. Copenhagen: Munksgaard, 1959. Thesis.

6 Gebbers J-O, Otto HF. Immunohistochemical and electron-microscopic observations on the local immune 
response in ulcerative colitis. Virchows Arch A [Pathol Anat and Histol] 1977; 374: 271-3.

7 Weissmann G. Activation of neutrophils and the lesions of rheumatoid arthritis. J Lab Clin Med 1982; 100: 322-33.

8 Boughton-Smith NK, Hawkey CJ, Whittle BJR. Biosynthesis of lipoxygenase and cyclo-oxygenase products from ${ }^{14} \mathrm{C}$-arachidonic acid by human colonic mucosa. Gut 1983; 24: 1176-82.

9 Sharon P, Stenson WF. Enhanced synthesis of leukotriene $\mathrm{B}_{\mathbf{4}}$ by colonic mucosa inflammatory bowel disease. Gastroenterology 1984; 86: 453-60.

10 Lauritsen K, Hansen J, Bytzer P, Bukhave K, RaskMadsen J. Effects of sulfasalazine and di-sodium azodisalicylate on colonic $\mathrm{PGE}_{2}$ levels determined by equilibrium in vivo dialysis of faeces in patients with ulcerative colitis and healthy controls. Gut 1984; 25 : 1271-85.

11 Lauritsen K, Laursen LS, Bukhave K, Rask-Madsen J. Effects of systemic prednisolone on arachidonic acid metabolites determined by equilibrium in vivo dialysis of rectum in severe relapsing ulcerative colitis. Gastroenterology 1985; 88: 1466.

12 Verspaget HW, Mieremet-Ooms MAC, Weterman IT, Pena AS. Partial defect of neutrophil oxidative metabolism in Crohn's disease. Gut 1984; 25: 849-53.

13 Binder V, Both H, Hansen PK, Hendriksen C, Kreiner $\mathrm{S}$, Torp-Pedersen $\mathrm{K}$. Incidence and prevalence of ulcerative colitis and Crohn's disease in the county of Copenhagen, 1962 to 1978 . Gastroenterology 1982; 83: 563-8.

14 Harvey RF, Bradshaw JM. A simple index of Crohn's disease activity. Lancet 1980; $1: 514$.

15 Tvede $\mathrm{M}$, Bondesen S, Nielsen $\mathrm{OH}$, Rasmussen SN. Serum antibodies to Bacteroides species in chronic inflammatory bowel disease. Scand J Gastroenterol 1983; 18: 783-9.

16 Böyum A. Isolation of leucocytes from human blood. Scand J Clin Lab Invest 1968; 21: suppl. 97: 9-29.

17 Nielsen OH, Bukhave K, Ahnfelt-Rønne I, Elmgreen J. Arachidonic acid metabolism in human neutrophils. Lack of effect of cyclosporine A. Int J Immunopharmacol 1986; 8: 419-26.

18 Samuelsson B, Borgeat P, Hammarström S, Murphy RC. Leukotrienes: A new group of biologically active compounds. Adv Prostaglandin Thromboxane Res 1982; 9: 1-18.
19 Borgeat P, Samuelsson B. Metabolism of arachidonic acid in polymorphonuclear leucocytes. $\mathrm{J}$ Biol Chem 1979; 254: 7865-9.

20 Lauritsen K, Laursen LS, Bukhave K, Rask-Madsen J. Effect of topical 5-aminosalicylic acid (5-ASA) and prednisolone on prostaglandin (PG) $\mathrm{E}_{2}$ and leukotriene (LT) $B_{4}$ levels determined by equilibrium in vivo dialysis of rectum in relapsing ulcerative colitis (UC). Gastroenterology 1985; 88: 1466.

21 Sharon P, Stenson WF. Metabolism of arachidonic acid in acetic acid colitis in rats. Gastroenterology 1985; 88: 55-63.

22 Rouzer CA, Shimizu T, Samuelsson B. On the nature of the 5-lipoxygenase reaction in human leukocytes: Characterization of a membrane associated stimulatory factor. Proc Natl Acad Sci USA 1985; 82: 7505-9.

23 Shak S, Goldstein IM. $\omega$-Oxidation is the major pathway for the catabolism of leukotriene $B_{4}$ in human polymorphonuclear leucocytes. J Biol Chem 1984; 259: 10181-7.

24 Goetzl EJ, Payan DG, Goldman DW. Immunopathogenetic roles of leukotrienes in human diseases. J Clin Immunol 1984; 4: 79-84.

25 Shak S, Reich NO, Goldstein IM, Ortiz de Montellano PR. Leukotriene $B_{4} \omega$-hydroxylase in human polymorphonuclear leukocytes. J Biol Chem 1985; 260: 13023-8.

26 Henderson WR, Klebanoff SJ. Leukotriene production and inactivation by normal, chronic granulomatous disease, and myeloperoxidase-deficient neutrophils. J Biol Chem 1983; 258: 13522-7.

27 Donowitz M. Arachidonic acid metabolites and their role in inflammatory bowel disease. Gastroenterology 1985; 88: 580-7.

28 Samuelsson B. Leukotrienes: a new class of mediators of immediate hypersensitivity reactions and inflammation. Adv Prost Thromb Leuk Res 1983; 11: 1-11.

29 DiRosa M, Flower RJ, Hirata F, Parente L, RussoMarie F. Nomenclature announcement. Antiphospholipase proteins. Prostaglandins 1984; 28: 441-2.

30 Nielsen OH, Bukhave K, Elmgreen J, Ahnfelt-Rønne I. Inhibition of 5-lipoxygenase pathway of arachidonic acid metabolism in human neutrophils by sulfasalazine and 5-aminosalicylic acid. Dig Dis Sci 1986 (in press).

31 Ament ME, Ochs HD. Gastrointestinal manifestations of chronic granulomatous disease. $N$ Engl J Med 1973; 288: 382-7. 